\title{
Linking Space and Labor Markets: Towards an Alternative Conceptualization of Labor Market Behavior
}

\author{
Dafna Kariv ${ }^{1}$ and Alan Kirschenbaum² \\ 1. School of Business Administration, College of Management, 7 Yitzhak Rabin Blvd \\ Rishon Lezion 75190 Israel \\ Telephone: +972-3-9634281; +972-3-5402571 \\ E-mail:karivd@colman.ac.il ; dafiran@nonstop.net.il \\ 2. William Davidson Faculty of Industrial Engineering and Management, Technion- Israel \\ Institute of Technology, Haifa, Israel \\ Telephone :+972-4-8294517, E-mail: avik@tx.technion.ac.il
}

KEYWORDS Labor markets; perceptions; labor behavior; environmental studies

\begin{abstract}
The objective of this paper is to explore a supplementary explanation of labor market behavior based on spatial perceptions. Along with existing labor market constructs, this can contribute, to a more encompassing explanation of labor behavior. Interviews were conducted among a nation-wide representative sample of employed Israelis in order to elicit how they define and choose labor markets. Multivariate analyses of the findings revealed that spatial perceptions of labor markets exist, are perceived in terms of multi-dimensional entities, and are demographically specific. Such a diversity of perceptions leads to different definitions of labor market boundaries and, thus, to possible entry constraints. We argue that these spatially derived perceptions can have a crucial impact on potential labor behavior and may help explain labor market formation.
\end{abstract}

\section{INTRODUCTION}

Labor markets constitute a dominant factor in the behavior of workers. They have a major effect on workers' mobility, commuting behaviors (Fevre, 1992; Kariv, 1999; Kariv and Kirschenbaum, 2000, 2006), organizational performance and/or work attitudes (Armitage and Conner, 2001; Bamberg, 2003; Richardson and Jensen, 2003). In past efforts to explain differences in behaviors, economists have relied on market forces, sociologists on exchange processes between employees' resources and jobs, and ecologists on the interrelated components of the human ecosystem. These macro-level explanations share the common underlying assumption that workers are guided by and react to market forces. There is, however, an additional explanation for labor behavior that views individual workers' perceptions of markets as an important factor. This "proactive" behavioral approach toward market choice has its roots in individual-space relationships, an area that has rarely been extrapolated to explain labor market

Correspondent author: Kariv Dafna, Ph.D. Doctor of Management, The School of Business Administration, College of Management, Israel. Rishon Lezion 75190 Israel. behavior. It is our intent in this paper to explore this alternative explanation of market behavior.

\section{Market Boundaries}

The traditional concept of a labor market (LM), while used extensively, has no general, uniform, broadly accepted definition (Ritchey, 1976). Labor markets are referred to as organizations (Dunlop, 1988), occupations (Wallace and Kallenberg, 1981), local labor markets (Lewin-Epstein and Semyonov, 1992), and ecological areas (Massey, 1979). This lack of similitude holds true for LM boundaries as well. Labor markets have been defined as physically bounded areas within cities (Champion and Green, 1992), as organizations or firms (Pfeffer and Cohen, 1984), as local geographic environments (Logan, 1978), and as industries or occupations (Wallace and Kallenberg, 1981). No unique and specific terminology has evolved to delimit LM areas, and specifically lacking in the research of this area is a general but well-established definition of where a labor market starts and ends. We can add to this absence of dimensions the lack of a symbolic-functional definition of LMs in terms of perceptions (Bonaiuto et al., 1999), attitudes, attachments, commitment, or power. As 
bounded space, labor markets can be represented as a form of cognitive symbolism expressed as feelings of belonging, attachment and bonding to a place (Genereux et al., 1983) or as a territory for social interactions, attaining social power and conflicts (Richardson and Jensen, 2003). Space in this sense acts as medium for social symbolism (Jensen and Richardson, 2001; Menachem and Spiro, 1989), but while space itself is objective and concrete, it confirms its meaning and appraisal subjectively, through people's perceptions (Rapoport, 1977). Thus, while the theoretical construct of LM is ubiquitous, its definitions vary and its boundaries fluctuate (Fernandez and $\mathrm{Su}$, 2004). As we will argue, the reason for this may lie in the fact that LMs are perceived differently by different groups of individuals.

The crucial litmus test of our "market perception" approach to labor behavior therefore depends on whether employees perceive labor markets differently, and if so, to what degree. If employees perceive labor markets differently, there is a distinct possibility that proactive choices and alternative labor market behaviors will emerge. In order to evaluate this possibility, it is important to recognize that spatial perceptions of the physical world are cognitive appraisals that act as a "mediating mechanism between the individual and the environment" (Rapoport, 1977). Expressed in simple terms, it is the way people give meaning to the external physical world, how they use this knowledge to structure their environment in their mind, and how both affect their spatial behavior (Rapoport, 1977; Ittelson et al., 1974; Altman and Low, 1992; Seagert and Winkel, 1990). The results of this process affect how perceived spatial boundaries are partitioned (Cohen, 1985), how spatial functionality is determined (Kitchin et al., 1997), how mental maps are conceived (Genereux et al., 1983), and how place-behavior patterns develop (Kent, 1990). Such perceptions act as a social technique for adaptation to natural and technological forces (Saegert and Winkel, 1990) with homogeneous groups generally concurring in the perceived attributes of space and its function.

Rapoport (1977) stressed this point by referring to the influence of demographic characteristics on the formation of spatial perceptions, which he based on the underlying assumption that homogeneous demographic groups tend to have similar perceptions of and reactions to the environment (Reitzes, 1986;
Cohen, 1985; Garling et al., 1984; Cadwallader, 1979). This issue is of crucial importance for understanding labor market constructs as it may help explain homogeneous spatial concentrations of employees in labor markets. Given this argument, the similarity of homogeneous groups' perceptions could, for example, provide an alternative explanation to the conundrum of the formation of enclave, protected or segregated LMs.

The present reconsideration of relevant demographic variables for testing this argument is based on a reading of previous findings and their relevancy to market behavior. Among the previously investigated factors linking spatial perceptions and spatial behavior have been gender (Altman and Churchman, 1994; Cohen and Huffman, 2003; Hanson and Pratt, 1988; Holding, 1992; Kent, 1990), and age and education (Curtis and Jackson, 1977; Sakamoto and Powers, 1995; Hanson, 1999). Extrapolating from these facets of spatial perceptions to the formation of LMs led us to speculate that LMs, which have both spatial and social attributes, may be defined - to one degree or another - by employees themselves. If this is the case, such perceptions may have a substantial impact on consequent labor-based behavior.

Embedding into these perceptions the symbolic meaning of space (reflecting "real world" attributes), and framing the combination into macro-level constructs, may provide an extended foundation for differentiating between labor markets. Incorporating dominant labor market definitions, we propose that various different perceptions of the labor market (LMPs) are generated by the major attributes of each LM, which are in turn based on the individual employees' references to their current jobs and potential external opportunities (job-seeking).

Thus, in the case of the economic labor market, perceived rewards for labor (income) constitute the predominant characteristic defining its boundaries (as well as affecting decisions to stay or leave a job, or search for a new one) (Madden and Chiu, 1990; Madden and White, 1980). Occupational labor markets delimit perceived boundaries of potential work sites based on the employee's current occupational characteristics (Becker, 1975, 1993). Organizational labor markets are more focused on the actual work organization (Doeringer and Piore, 1971), and employees view them in terms of their interpretation of internal organizational processes. 
Segmented labor markets are perceived in terms of how individuals view the social and human attributes of their colleagues, that is, the degree to which they are similar in life style, social status or other social attributes (Hanson and Hanson, 1985; Hanson et al., 1997; Little and Triest, 2002); the focus is therefore directed toward the individuals' perceptions of co-workers' attributes rather than on actual job or regional attributes. Professional labor markets are based on how individuals' formal training and/or professional attributes affect the boundaries of opportunity. Local labor markets are marked by symbols associated with the physical attributes of a geographic area (Hawley, 1984; Stolzenberg and White, 1984; Wyly, 1999), such as proximity to one's residence, available or accessible transportation, etc. Finally, the general labor market refers to an open boundary market, which is simply a place to "make a living".

This all-embracing definition of the labor market, differs from, and supplements, earlier definitions which treat the LM as a nondiscrimated arena.

\section{HYPOTHESES}

The two research questions are exploratory in nature (1) Are there differences in employees' perceptions of their labor market? This question addresses the differences in employees' perceptions of their labor markets and was investigated both by delineating employees' spatial definitions of their "ideal", or favored, labor market and by analyzing the replies on their definitions of their actual labor market; (2) Are there perceptions of labor markets shared by employees of the same gender, age level, educational level or family status?

\section{METHODOLOGY}

\section{Research Design}

To confirm the significance of perceptions in defining labor markets and their boundaries necessitated devising a research strategy that would tap employed persons' perceptions of their work and work place. This would allow us to determine the existence and extent of variations in definitions of LMs and their boundaries. Due to the complexity of testing and validating the concept of LMPs, two kinds of data were employed. The first consists of responses to questions related to the respondents' current jobs. The second focuses on seeking a new job and ranking the importance of alternative markets.

The rationale for focusing on "current job" and "job-seeking" was that each represented one possible way in which employees could evaluate their "markets". In the first case, in which the reference point was the currently-held job, the assumption was that the respondent's present work environment would act as an influential referent in defining her or his perceptions of labor markets in general. In the second case, that of job-seeking, employees would have to demarcate market boundaries on the basis of their perceptions. This demarcation would allow us to discover the type and scope of their perceived market boundaries. To attain these objectives we chose to do a field survey and to develop a set of measures of the labor market that would elicit answers to such basic questions as whether people have different perceptions of what a labor market is.

To find answers to these concerns, we began by developing a questionnaire that focused on traditional LM perceptions. This provided us with the data to measure the extant, traditional labor market constructs against perceptions of such markets, and to judge their applicability. It would also, we hoped, provide a better understanding of the processes that affect LM definitions and consequent market choices. To decipher how perceptions define labor markets, we choose two major consecutive measuring devices. The first was a series of open-ended questions through which respondents would define their current $\mathrm{LMs}$, while the second set was based on reactions to existing traditional constructs. Open-ended questions were presented first in order to increase reliability and unbiased (intuitive) responses to questions relating to labor market perceptions.

\section{Definitions of the Variables}

\section{Dependent Variable - LMPs}

The construction of the key variables, which would define labor markets, was based on responses to a series of conditional questions. These questions were based on a series of pretests of optional measures that took into account the cultural milieu surrounding work and the work place. In the first case, a series of open-ended 
questions were asked, "What do you do for a living?" followed by "Describe briefly what your job entails." The combination of responses was intended to provide baseline information, which covered all the basic properties of the major LM concepts expressed in the literature. The replies to these "open ended" questions were evaluated by two techniques: an occupational categorization, provided by the Israel Central Bureau of Statistics; and a more complicated content analysis of the answers. The content analysis was based on the researchers' agreed-upon categorization of the responses, which included more than the simple description of the occupation.

Overall, nine "market types", based on fortynine (49) categories or combinations of categories expressed by the respondents, emerged as the most frequently cited. These included perceived markets whose boundaries depended on (1) physical locality; (2) general organization type; (3) occupational specialization; (4) specific product/service line; (5) status position; (6) type of customer; (7) type of employer; (8) being salaried or self-employed; and (9) combinations of these attributes.

Taking this a step further, and on the basis of a set of the pre-coded traditional market categories, we asked each respondent to define his or her labor market. In this case, we asked what constitutes the boundaries of each individual's preferred labor market, and did this through the medium of a job-seeking variable: "If you were not already in the labor market, and you were exploring job possibilities, which of the alternative markets would you look at?" The seven concepts of labor market perceptions noted above were presented as independent alternative market concepts, and the respondents were asked to relate to each one separately. This was followed by a similar question to which the respondent was asked to respond by choosing the single most important market. This provided information on the outer limits of perceived market boundaries within which a job would be sought, as well as variability (first ranked) in market importance when searching for a job. We sought to understand the degree of relevancy of each separate market as an additional means of determining the degree of market differentiation.

The research assumptions concerning labor markets and their boundaries were thus analyzed by two separate measures that, taken together, formed a broad picture of perceived labor market constructs: the respondents' first, unbiased answers to an open-ended question about LM components based on their current jobs, and their answers to a "closed" question based on precoded market categories specifically asking about potential market boundary preferences in a job-search situation This combination of two sets of questions, with different data collection methods and measuring present and potential markets, provided us with the means to gather a more complete and valid picture of how labor markets are perceived.

\section{Independent variables}

The independent variables included in the measurements were assessed through the respondents' self-reports and included: gender; age; educational level, measured by reported number of years of schooling; age of respondents' youngest child; and familial salary, assessed by joint salaries of respondent and spouse.

\section{Data Source}

The data was generated from a field survey based on individual, face-to-face interviews with a nation-wide representative sample of adult Israeli Jewish households. A total of 723 persons, evenly divided between men and women, comprised the sample.

\section{Market Perceptions}

The primary question we explored was whether there are differences in employees' perceptions of their labor markets. To answer this question we first looked at responses to the second, "closed" question, in which the respondents chose different markets from the seven pre-determined LM categories: economic, occupational, organizational, segmented, professional, local and general. We chose to examine these responses first, as it would give us an indication of how well traditional LM constructs matched the respondents' perceptions of these markets. To explore the possibility that employees have various understanding of LMs, the respondents were asked to choose from the market categories in the "closed" question, the labor market most important to them. Their responses were elicited on the basis of a job- 
seeking question ("If you were looking for a job..."). An initial simple frequency distribution of responses to the seven pre-coded categories supported the notion that market boundary perceptions are diverse (see Table 1). The distribution of the responses indicated that most of the respondents $(47.6 \%)$ consider the economic LM of prime importance in their labor behavior while at the other extreme; the general LM was practically negligible, with only three percent choosing it as preferred market. Between these extremes were occupational LM (nearly 14\%) and local LM (about 12\%) LMs while organizational and professional LMs (both around 8\%) were somewhat less frequently chosen LMs.

These results provided initial support to the premise that the seven categories were indeed appropriate benchmarks for gauging employees' perceptions of labor markets.

We went a step further by probing the degree to which respondents perceived these labor market categories as separate entities conceptual and physical. To do this, we employed a Multivariate analysis (MANOVA), which allows for a comparison of groups delineated by categorized independent variables. The analysis compared group differences in a set of interval dependent variables, with the seven distinct labor market categories as dependent variables. The results revealed an overall significant $F$ of the analysis (Wilks $\lambda=0.755, F(1,615)=268.181$, $\mathrm{p}<.001 * *)$. The means for the seven given labor market categories indicated that the respondents' ranking of LM preferences were significantly different from each other, as follows: local LMP $(F=382.332, p<0.001 * *)$; professional LMP $(F=$
240.321, $p<0.001 * *)$; organizational LMP $(F=$ $167.801, p<0.001 * *)$; occupational LMP $(F=$ $374.508, p<0.001 * *)$; general LMP $(F=164.577$, $p<0.001 * *)$; segmented LMP $(F=172.688, p<$ $0.001 * *)$; and economic LMP $(F=1293.121, p<$ $0.001 * *)$.

The results suggest that although employees have different perceptions of labor markets, they respond differently to the relevancy that each type of market has for them. In many cases, there is little match between the two - the subjective perception and the objective relevancy.

\section{Respondents' Definitions of Labor Markets}

At this point we turned to the responses to "open-ended" question, based on the respondents' initial replies to the question of how they make their living, which focused on their current job. Based on a content analysis of the frequency of clusters in the_replies, nine major market categories were generated. A clear set of perceived market categories emerged, one which differed radically from the "closed" pre-coded traditional LMs question. The distribution of the content analysis of the responses in Table 1 revealed that most of the respondents describe their current jobs by incorporating more than one LM measure, with status position and occupation and organization the leading characteristics in descriptions of their current jobs. Additionally, Table 1 reveals, for example, the complete absence of the economic parameter of market perceptions, which figured so dominantly when pre-coded market measures were employed. Apparently, when given a chance to express what they

Table 1: Distribution of self-defined market categories and pre-coded labor market categories

\begin{tabular}{|c|c|c|c|c|c|}
\hline $\begin{array}{l}\text { Self-defined Market Categories- } \\
\text { Current Job }{ }^{1}\end{array}$ & $N$ & $\%$ & $\begin{array}{c}\text { Pre-coded Labor Market } \\
\text { Categories-Job Choices }\end{array}$ & $N$ & $\%$ \\
\hline Status Position + Other 2 & 139 & 19.4 & Economic & 344 & 47.6 \\
\hline Occupation + Organization & 138 & 19.3 & Occupational & 100 & 13.8 \\
\hline Occupation + Specialization & 125 & 17.5 & Local & 88 & 12.2 \\
\hline Occupation & 110 & 15.4 & Organizational & 61 & 8.4 \\
\hline \multicolumn{6}{|l|}{ Occupation + Specialization +} \\
\hline Organization & 57 & 8 & Professional & 60 & 8.3 \\
\hline Occupation + Other ${ }^{2}$ & 51 & 7.1 & Segmented & 48 & 6.6 \\
\hline Specialization & 38 & 5.3 & General & 22 & 3 \\
\hline Organization & 32 & 4.5 & Total & 723 & 100 \\
\hline Specialization + Organization & 25 & 3.5 & & & \\
\hline Total Sum & 715 & 100 & & & \\
\hline (missing) & -8 & & & & \\
\hline
\end{tabular}

${ }^{1}$ Content analysis of responses to the question "How do you make your living?

2 "Other" includes an extremely small number of responses which encompassed various alternative descriptions of labor markets. 
perceive to be their current labor market, the respondents focus primarily on their professional status, occupation and organizational affiliation.

Of particular interest was the use, by approximately seventy-five percent $(75 \%)$ of the respondents, of a combination of two or even three definitions to describe their labor market, indicating that their LMPs were multi-dimensional. This is in stark contrast to the closed and precoded question that, due to its methodological format, did not allow for such multi-dimensional self-expression. There thus seem to be no clearcut and ubiquitous LM boundary markers. Most of the respondents tended to favor a definition of their LM bounded primarily by occupational parameters: approximately $57 \%$ cite their occupation as a component in their labor market definition, and of these, more than $15 \%$ use it exclusively. The complexity of these selfdefinitions can be seen in the finding that the remaining third of the sample did not cite the occupational component to describe their links to a labor market but, rather, referred to characteristics of the organization, in which they are employed, or their status or specialization, without mentioning their actual occupation. The two boundary definitions cited most often are related to the respondents' status position $(19.4 \%)$ and the combined characteristics of their organization and occupation (19.3\%). This was followed by a combination of their occupation and specialization (17.5\%). Again, responses focusing solely on occupation were cited least frequently $(15.4 \%)$. Unlike the answers proffered when pre-coded traditional market categories were presented to the respondents, open-ended expressions of markets based on current jobs provided a different picture of what comprised market boundaries.

Overall, these results confirm the complex notion of LMs definitions by stressing that a simple, onedimensional definition of LMs does not match the reality of how individuals perceive them.

\section{The Labor Market as a Shared Perception}

The second research question, that asked whether groups having similar demographic

Table 2: F, Means and Standard Deviations for personal characteristics and pre-coded LM categories

\begin{tabular}{|c|c|c|c|c|c|c|c|}
\hline $\begin{array}{l}\text { Personal } \\
\text { indicators }\end{array}$ & $\begin{array}{l}\text { Pre-coded LM's } \\
\text { categories }^{1}\end{array}$ & $\begin{array}{l}\text { Mean } \\
\text { Square }\end{array}$ & $F$ & $p$ & $\begin{array}{l}\text { Wilks' } \\
\text { lambda }\end{array}$ & $F$ & $p$ \\
\hline Children's Age & & & & & 0.99 & 0.84 & 0.554 \\
\hline \multirow[t]{8}{*}{ Gender } & & & & & 0.973 & 2.319 & $.024 *$ \\
\hline & Local & 1.462 & 6.312 & $.01 * *$ & & & \\
\hline & Professional & 0.54 & 2.72 & $.05 *$ & & & \\
\hline & Organizational & 0.055 & 0.339 & 0.56 & & & \\
\hline & Occupational & 0.234 & 1.027 & 0.31 & & & \\
\hline & General & 0.08 & 0.48 & 0.48 & & & \\
\hline & Segmented & 0.156 & 0.923 & 0.33 & & & \\
\hline & Economic & 0.25 & 1.14 & 0.28 & & & \\
\hline \multirow[t]{8}{*}{ Age } & & & & & 0.946 & 4.795 & $.000 * *$ \\
\hline & Local & 1.718 & 7.42 & $.00 * *$ & & & \\
\hline & Professional & 1.069 & 5.382 & $.02 *$ & & & \\
\hline & Organizational & 4.465 & 27.601 & $.00 * *$ & & & \\
\hline & Occupational & 0.361 & 1.583 & 0.21 & & & \\
\hline & General & 0.092 & 0.547 & 0.46 & & & \\
\hline & Segmented & 1.025 & 6.025 & $.01 * *$ & & & \\
\hline & Economic & 0.421 & 1.819 & 0.17 & & & \\
\hline \multirow[t]{8}{*}{ Educational Level } & & & & & 0.947 & 4.705 & $.000 * * *$ \\
\hline & Local & 0.945 & 4.079 & $.05 *$ & & & \\
\hline & Professional & 1.294 & 6.516 & $.01 * *$ & & & \\
\hline & Organizational & 0.006 & 0.035 & 0.85 & & & \\
\hline & Occupational & 4.461 & 19.587 & $.00 * *$ & & & \\
\hline & General & 7.949 & 0 & 0.98 & & & \\
\hline & Segmented & 0.219 & 1.293 & 0.25 & & & \\
\hline & Economic & 0.428 & 1.955 & 0.16 & & & \\
\hline Familial Salary & & & & & 0.99 & 0.834 & 0.559 \\
\hline
\end{tabular}

${ }^{1}$ Only pre-coded LM categories of significant covariates are included.

$* p<.05 ; * * p<.01 ; * * * p<.001$ 
characteristics share similar perceptions of LMs, was investigated by the pre-coded categories of optional LMs. A Multivariate (MANOVA) test was conducted with the pre-coded responses for each market as dependent variables, and gender, age, educational level, number of children under 5 years of age, and familial income as covariates. The results (Table 2) revealed statistical significance for gender, age and educational level, with $F$ scores of the Tests of Between-subjects Effects indicating that gender is significantly associated with local LMPs; age with local, professional, organizational and segmented LMPs; and educational level with local, professional and occupational LMPs.

A correlation Matrix reveals the directions of the relationship between personal characteristics and LMPs: women more than men tend to prefer a local LM for potential alternative jobs; age was positively associated with local, professional, organizational and segmented LMPs; and educational level was significantly and negatively related to local LMPs and positively related to professional and occupational LMPs.

\section{SUMMARY AND CONCLUSIONS}

The concept of LM has almost always been viewed from a macro-level perspective, the natural outcome of economic and sociological dominance in the area of labor behavior. We have taken a different approach by arguing that labor markets are also perceived spatial units. The key difference in such a perspective is that while market forces or sociological processes are inarguably very relevant to the formation of market boundaries, these boundaries are not perceived in the same way by different individuals, whose particular characteristics lead them to focus their attention on certain qualities of the labor market and its boundaries. To tackle the problem of measuring such indeterminate LMPs, we opted for a twopronged research inquiry: open-ended selfdefinition and pre-coded traditional labor market measures associated with the respondents' current jobs in tandem with a job-seeking measure for evaluating potential alternative jobs. By focusing on both current job and job-seeking, we sought, in fact, to probe labor market perceptions at two different levels. In this way, we were able to evaluate both the relevancy of traditional market concepts among demographically homogeneous groups and the impact of their shared perceptions. The nationwide representative sample of employed household members, which formed the data base for the study, provided the means to test our ideas, and the preliminary results more than justified the effort entailed in encompassing such a large and widely-dispersed sample population.

The overall results clearly suggest that the perception of a traditional labor market construct is not a shared phenomenon. There appeared to be no "one single" labor market, but rather distinct markets based on their perceived attributes. There was also, however, strong evidence to suggest that the traditional constructs are alive and well. This applied for both measures of the labor market perceptions examined in the present study - one measure anchored in the traditional closed, precoded construct and the other perceived according to open-ended self-defined market categories. However, and most importantly, we found that employees, as individuals and as homogeneous groups, perceived LMs in dissimilar ways: LMs meant different things to different employees and are accordingly characterized by various - and not necessarily identical - attributes. Second, the results stress that present occupation constitutes a central (but not the sole) component in generating perceptions of labor markets. In this case, the most interesting finding, and we believe the salient one, was that occupation was less frequently described as the sole element for demarcating labor market boundaries. Rather, one or more other labor market determinants (attributes of organizations, status positions and specialization) were combined with present occupation to create a multi-dimensional construct. Thirdly, there was a clear demarcation in the predominance of perceived economic determinants of labor markets.

The choice and relevancy of the economic labor market was clearly visible when based on measures of aspired labor markets, as in jobseeking situations, but far less apparent when measured in terms of the current job. This may be a particularistic facet of Israeli culture, which is based on a strongly credential job culture rather than on an intrinsic-extrinsic one. However, it, simultaneously points to a perception of the boundaries of labor markets for those seeking jobs, as well as, to a confined symbolic size when viewed from the perspective of the current job.

These results illuminated the possibility that the diverse perceptions of labor markets might be associated with group traits. Employing a 
multivariate MANOVA analysis to evaluate this possibility, we found that this was generally the case. Varying degrees of demographic homogeneity based on gender, age and level of education were predominant in forming perceptions of the various pre-coded market categories.

An additional implication of our findings suggests that job-holders attempt to symbolically enlarge their "spatial attainments" within labor markets. The emphasis here is on LMs perceived as multi-dimensional constructs. The focus on, and beyond, the occupational market suggests that employees view the labor market in terms of the potential territories they can enter. By doing so, they do not limit themselves explicitly to the occupational market, but also see themselves interacting in professional or other labor markets. The greater the number of symbolic territories the worker succeeds in entering, the more prestigious the status he/she achieves in the labor market.

Overall, the results of this exploratory study support the argument that not only do perceptions of LM boundaries exist, but they vary considerably and are based on diverse combinations of LM attributes. As such, the transformations of these perceptions into behavior can have a crucial impact on labor behavior. From these preliminary results, it seems that applying only traditional macro-level constructs of labor markets, as a pre-condition to labor behavior may not suffice. As shown in this paper the facts are that perceptions are forcefully interwoven into different participants' definitions of labor markets, and that the boundaries of these markets overlap and fluctuate in tandem with the characteristics of each participant. Some perceptions of labor markets have clear links to shared group traits, others to more socially sensitive process characteristics. This, in itself is convincing evidence that employees are feeling and thinking human beings, and they do not necessarily follow the clearly defined boundaries that rational or institutional models have set for them.

\section{ACKNOWLEDGMENTS}

This research was supported by the Taub Prize, Technion. All opinions are those of the authors alone.

\section{REFERENCES}

Altman, I. and A. Churchman. 1994. Women and the Environment: Human Behavior and the Environ- ment, Advances in Theory and Research, 13. New York: Plenum.

Altman, I. and S. Low. 1992. Human Behaviour and Environments: Advances in Theory and Research, 12: Place Attachment. New York: Plenum.

Armitage, C.J. and M. Conner. 2001. "Efficacy of the Theory of Planned Behaviour: A Meta-Analytic Review." British Journal of Social Psychology, 40: 471-499.

Bamberg, S. 2003. "How Does Environmental Concern Influence Specific Environmentally Related Behaviors? A New Answer to an Old Question." Journal of Environment Psychology, 23(1): 21-32.

Becker, G. S. 1975. Human Capital: A Theoretical and Empirical Analysis with Special Reference to Education. New York: National Bureau of Economic Research.

Becker, G. S.1993. Human Capital: A Theoretical and Empirical Analysis, with Special Reference to Education. 3rd edition. Chicago: The University of Chicago Press.

Bonaiuto, M., A. Aiello, M. Perugini, M. Bonnes and A. Paola Ercolani. 1999. "Multidimensional Perception of Residential Environment Quality and Neighborhood Attachment in the Urban Environment." Journal of Environmental Psychology, 19(4): 331352.

Cadwallader M. 1979. "Problems in Cognitive Distance Implications for Cognitive Mappin." Environment and Behaviour, 11(4): 559-576.

Champion, A.G. and A. E. Green. 1992. "Local Economic Performance in Britain during the Late 1980s: The Result of the Third Booming Towns Study." Environment and Planning, 24: 243-272.

Cohen, A. P. 1985. The Symbolic Construction of Communities. London and New York: Ellis Horwood Limited Publishers-Chichester Tavistock Publications.

Cohen, P. N. and M. L. Huffman. 2003. "Occupational Segregation and the Devaluation of Women's Work across U.S. Labor Markets." Social Forces, 81(3): 881-908.

Curtis R. F. and Jackson, E.F. 1977. Inequality in American Communities. New York: Academic Press.

Doeringer, P. B. and M. J. Piore. 1971. Internal Labor Markets and Manpower Analysis. Lexington, MA.: Health Lexington Books.

Dunlop, J. 1984. Industrial Relations and Economics: The Common Frontier of Wage Determination. In Industrial Relations Research Association, Proceedings of the Thirty-Seventh Annual Meeting (pp. 9-23). Madison: Industrial Relations Research Association.

Fernandez, R. M. and C. Su. 2004. "Space in the Study of Labor Markets." Annual Review of Sociology, 30: 545-569.

Fevre, R.1992. The Sociology of Labour Markets. London, Great Britain: Harvester Wheatsheaf.

Garling T., Book, A. and E. Lindberg. 1984. "Cognitive Mapping of Large-Scale Environments the Interrelationship of Action Plans, Acquisition, and Orientation." Environmental Behavior, 16(1): 3-34.

Genereux, R., L. M. Ward and J. A. Russell. 1983. "The Behavioral Component in the Meaning of Places." Journal of Environmental Psychology, 3: 43-55. 
Hanson, S. 1999. "Is Feminist Geography Relevant?" Scottish Geographical Journal,115(2): 133-141.

Hanson, S. and P. Hanson. 1993. "The geography of everyday life", (pp. 249-269) in T. Garling, and R. G. Golledge (eds.), Behavior and Environment: Psychological and Geographical Approaches. North Holland: Elsevier Science Publishers B.V.

Hanson, S., T. Kominiak and S. Carlin.1997. "Assessing the Impact of Location on Women's LM Outcomes: A Methodological Exploration." Geographical Analysis, 29(4): 281-297.

Hanson, S. and G. Pratt. 1988. "Spatial Dimensions of Gender Division in a Local Labor Market." Urban Geography, 6: 193-219.

Hawley, A. 1984. "Human Ecological and Marxian Theories." American Journal of Sociology, 89(4): 904-917.

Holding, C. S. 1992. "Cluster and Reference Points in Cognitive Representations of the Environment." Journal of Environmental Psychology, 12: 45-55.

Ittelson, W. H., H. Proshansky, L. Rivlin and G. Winkel. 1974. An Introduction to Environmental Psychology. New York: Holt, Rinehart and Winston.

Jensen, O. B. and T. Richardson. 2001. "Nested Visions: New Rationalities of Space in European Spatial Planning." Regional Studies, 35(8): 703-717.

Kariv, D. 1999. Spatial Boundaries of Labor Markets' Perceptions: An Empirical Assessment. Ph.D. Thesis, Technion, Haifa, Israel (Hebrew).

Kariv, D. and A. Kirschenbaum. 2000. Gender Perceptions of the Labor Markets: An Exploration of Proactive Selection into Labor Markets. Working Paper, 25, Technion, Israel

Kariv, D. and A. Kirschenbaum. 2006. "Collective Spatial Perceptions of Men and Women Commuters: Linking Space, Jobs and Activity." Journal of Human Ecology (accepted July, 9, 2006).

Kent, S. 1990. "Partitioning Space Cross-Cultural Factors Influencing Domestic Spatial Segmentation." Environment and Behavior, 23(4): 438-473.

Kitchin, R. M., M. Blades and R. G. Golledge. 1997. "Relations between Psychology and Geography." Environment and Behavior, 29(4): 554-573.

Little, J. S. and R. K. Triest. 2002. "The Impact of Demographic Change on the U.S. Labor Markets." New England Economic Review, 1: 47-69.

Logan, J. R. 1978. "Growth, Politics and Stratification of Places." American Journal of Sociology, 84 (2): 404-416.
Madden J. F. and L. C. Chiu. 1990. "The Wage Effects of Residential Location and Commuting Constraints on Employed Married Women." Urban Studies, 27: 353-369.

Madden, J. F. and M. J.White. 1980. "Spatial Implications of Increases in the Female Labor Force: A Theoretical and Empirical Synthesis." Land Economics, 56(4): 432-446.

Massey, D.1979. "In What Sense a Regional Problem?" Regional Studies, 13: 233-244.

Menachem, G. and S. Spiro. 1989. "Urban Neighborhoods and the Quest for Community: Implications for Policy and Practice." Community Development Journal, 24(1): 29-49.

Pfeffer, J and Cohen, Y. 1984 "Determinants of Internal Labor Markets in Organizations." Administrative Science Quarterly, 29: 550-572.

Rapoport, A.1977. Human Aspects of Urban Form. London, Great Britain: Pergamon.

Reitzes, D. C.1986. "Urban Identification and Downtown Activities: A Social Psychological Approach.” Social Psychology Quarterly, 49(2): 163-179.

Richardson, T. and O. B. Jensen. 2003. "Linking Discourse and Space: Towards a Cultural Sociology of Space in Analyzing Spatial Policy Discourse." Urban Studies, 40(1): 7-22.

Ritchey, P.N. 1976. "Explanations of Migration." Annua7 Review of Sociology, 2: 363-404.

Saegert, S. and G. H. Winkel. 1990. "Environment Psychology.” Annual Review of Psychology, 41: 441477.

Sakamoto, A. and D. A. Powers. 1995. "Education and the Dual Labor Market for Japanese Men." American Sociological Review, 60: 222-246.

Lewin-Epstein, N. and M. Semyonov. 1992. "Local Labor Markets, Ethnic Segregation, and Income Inequality." Social Forces, 70(4): 1101-1119.

Stolzenberg, R. M. and L. J. Waite. 1984. "Local Labor Markets, Children and Labor Force Participation of Wives." Demography, 21(2): 157-169.

Wallace M. and A.L. Kalleberg. 1981. "Economic Organization of Firms and Labor Market Consequences: Toward a Specification of Dual Economic Theory", (pp. 77-117) in: I. Berg (ed.). Sociological Perspectives on Labor Markets: New York: Academic Press.

Wyly, E. K. 1999. "Local Labor Markets and Occupational Sex Segregation in an American Metropolis." Journal of Urban Affairs, 21(1): 1-33. 